\title{
The Information Strategy Developing for Municipal Solid Waste Management Based on Cognitive Modelling
}

\author{
Vladimir Gvozdev \\ Ufa State Aviation Technical \\ University \\ Ufa, Russia \\ wega55@mail.ru
}

\author{
Oksana Bezhaeva \\ Ufa State Aviation Technical \\ University \\ Ufa, Russia \\ obezhaeva@gmail.com
}

\author{
Anastasiya Khamidullina \\ Ufa State Aviation Technical \\ University \\ Ufa, Russia \\ namukha5@gmail.com
}

\begin{abstract}
The paper discusses the strategy developing for an effective management of municipal solid waste. The significant factors for modelling have been identified. A cognitive model, taking into account to the diversity of initial data is proposed. To solve this problem, expert-statistical estimates are proposed. Cognitive maps that correspond to the different strategies for the municipal solid waste management in industrialized areas have been constructed, specifically, the prevalence of waste storage, storage and sorting, sorting and processing. Proposed cognitive model allows to make the primary qualitative analysis of the problem situation, allows to identify the relationship and influence of various factors. This analysis reduces the level of uncertainty in waste management. The main purpose of strategies developing for municipal solid waste managing based on cognitive modeling is to reduce the uncertainty of the problem situation and make a consolidated decision, taking into account of various stakeholders interests, including population, government agencies, businesses and specialists in territorial systems management, the scientific community and public organizations.
\end{abstract}

Keywords-cognitive model, focus groups of actors, solid waste management, industrialized areas, significant factors, primary qualitative analysis

\section{INTRODUCTION}

Urban development, raising of the population living standard and increasing of human economic activity create one of the urgent problems of our time the problem of the negative waste impact on the environment and public health. Today, recycling is one of the most pressing environmental problems. Every year, human consume more and more products, increase production rates, respectively, increasing the total amount of waste. According to statistics, the level of pollution in modern Russian cities is quite high. All the garbage is brought to landfills storage, where it successfully accumulates and fills a large area. Today's realities with a lot of unresolved issues of recycling and disposal of garbage are rooted in the 1990s. In that time the use of waste paper and recycled materials stopped. Almost at the same time, a new consumer culture was formed, in which the amount of garbage increased dramatically. All this coincided with the beginning of the plastic era. In just a few years, not only the country rapidly changed, but also the composition of household waste, in which disposable plastic dishes, plastic containers, plastic bottles and packaging have to meet more often. Prior to sorting and recycling of waste in the state and even more so in the society hands did not reach. Waste disposal is mainly carried out by means of garbage storage in the large dump - landfills storage, size of which every day is increasing. Until recently, in regions, and in the hole country no one going to deal with the problem of waste disposal and recycling, fortunately the situation is beginning to change.

It is worth to consider that the solution of this problem should be approached on the basis of the intersubjective and converged management $[1,2,3]$ theory in the interests of the various stakeholders: representatives of public authorities, government, business, the scientific community, public organizations.

\section{DIFFERENT STRATEGIES FOR MUNICIPAL SOLID WASTE MANAGEMENT IN INDUSTRIALIZED AREAS BASED ON COGNITIVE MODELLING}

The waste management system belongs to the class of open complex systems. Waste management has to be carried out under conditions of uncertainty, due to:

- Lack of knowledge about the mechanisms of the influence of waste on the territorial systems state;

- The difference in goals and motives of representatives of government, businesses and population in the problem situation resolving.

- The presence of a large number of interconnected subsystems, including temporary storage, collection, transportation and disposal of waste;

- Limited data describing the processes of occurrence, collection, storage, recycling;

- High dynamics, due to the rapid change of the situation in the field of waste management;

- Insufficient knowledge about cause-effect relations of waste and conditions of the 
surrounding environment and health of the population.

The management of such systems under the action of a large number of external and internal factors is extremely difficult, since it is associated with the need for rapid management decisions in the face of uncertainty, a shortage of resources and the occurrence of possible abnormal situations. These tasks can be solved by using cognitive modeling, which allows to identify possible options for the development of situations and to qualitatively assess the attainability of the goal in these situations. The methodology of cognitive modeling allows to analyze and make decisions in uncertain situations, including the field of management and the organization.

This paper discusses the construction of cognitive models corresponding to different strategies for municipal solid waste management in industrialized areas, specifically: the prevalence of waste storage; storage and sorting; sorting and processing.

The composition of a cognitive model factors and the relationship between concepts reflects the perception of a problem situation by different focus groups of actors. One of the focus groups are scientists and the models take into account their motivational aspects.

Under the problem situation the semistructured situation with fuzzy goals is understood $[4,5]$.

Today, the problem situation with solid waste is obvious for all regions of Russia, including the Republic of Bashkortostan, where more than 1 million tons of waste (>97\% of the total volume) is exported for disposal to landfill annually (the total amount generated to the 2016 were about 24 million tons of waste) $[6,7]$.

The apparatus of cognitive maps is well suited to describe this problem situation, since cognitive maps of various types are the main tool for the study of semi-structured situations $[8,9]$.

In the early stages of projects one of the techniques is the use of a sign-oriented graph, in which vertices are graph concepts (factors linked between and affecting the situation being characterized) and edges characterize the mutual influence of the system components on each other (causal relationships between factors).

In cognitive maps, concept signs are used: positive and negative. If two concepts are connected with each other by a positive connection, then the increase in value of one of the concepts leads to an increase in the other. If two concepts are connected by a negative connection, then an increase in the value of one of the concepts leads to a decrease in the value of the other. It is necessary to take into account the presence of positive (reinforcing) and negative (stabilizing) feedbacks in the systems.

The presence of positive and negative feedback is a formal sign of a nonlinear system. The presence of positive and negative feedback contours explains the process of system status changing, which may be converging, diverging, or oscillating for a given structure of the system components status depending on the point of impact.

\section{COGNITIVE MODEL WITH THE PREVALENCE OF WASTE STORAGE}

Cognitive structurization begins with the definition of the studied system objects (characterized both quantitatively and qualitative) and establishment of communications between its. At the initial stage for the compilation of a cognitive model, it is necessary to select a list of significant factors:

1) Population living conditions;

2) Waste;

3) Waste disposal;

4) The condition of the environment;

5) Costs of parrying;

6) Financial load on population;

7) Incomes of the population.

This option reflects the current situation, namely the model of municipal solid waste management consists of 7 components, where living conditions correspond to the state of human health, nutrition, life expectancy, etc.

Construct the first cognitive model corresponding to the current situation of waste management, namely, the prevalence of waste storage. This model is shown on Fig. 1.

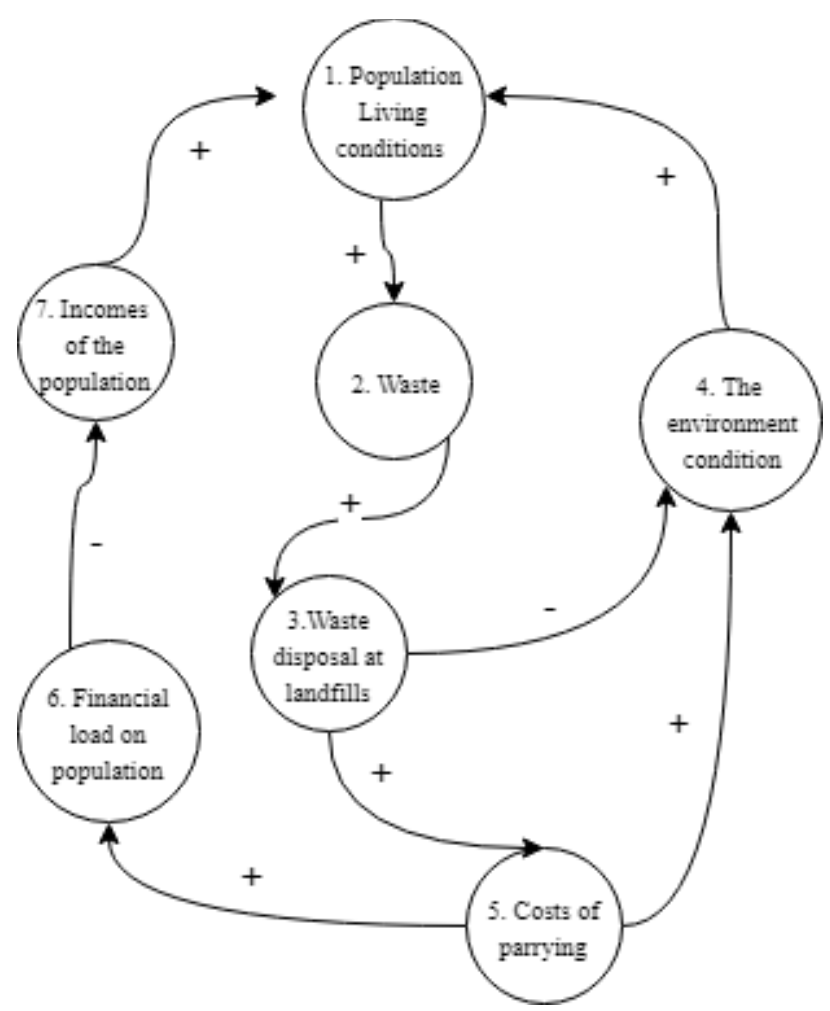

Fig. 1. Cognitive model corresponding to the current situation of waste management, namely, the prevalence of waste storage 
The concept of "Population living conditions" directly affects the concept "Waste". Since the higher level of life, than the higher the consumption level and the waste amount increases. At this stage, the basic principle of waste disposal is dumping at landfills storage; the more waste there is, the more space is needed for disposal, and this has a negative impact on the environment.

In order to reduce the negative impact on the environment and cope with the already accumulated amount of waste at landfills storage, the number of which is increasing regular, we need tools, methods, technologies and equipment. The financial load at the same time falls on the shoulders of the population, through an increase of tariff for garbage removal, it affects to the income of the population and the population living conditions.

This strategy should not remain priority, it is necessary to consider other options for waste disposal which will reduce negative impact on environment condition the and also will lower the financial load on the population, at the expense of funds received from recycling and sorting of waste and garbage.

\section{COGNITIVE MODEL WITH THE PREVALENCE OF WASTE SORTING AND RECYCLING}

Considering information from external sources, articles $[10,11,12]$, the experience of other countries, which have switched to alternative methods of waste management, it is proposed to build a cognitive model focused on waste sorting and recycling. Construct the another cognitive model waste management with the prevalence of waste sorting and recycling, the model is shown in Fig. 2. In this model, the list of significant factors is expanded.

List of significant factors:

1) Population living conditions;

2) Waste;

3) Costs of environment protection;

4) The environment condition;

5) Disposal of unprocessed waste;

6) Waste Sorting;

7) Recycling;

8) Filling of the local budget;

9) Financial load on population;

10) Incomes of the population.

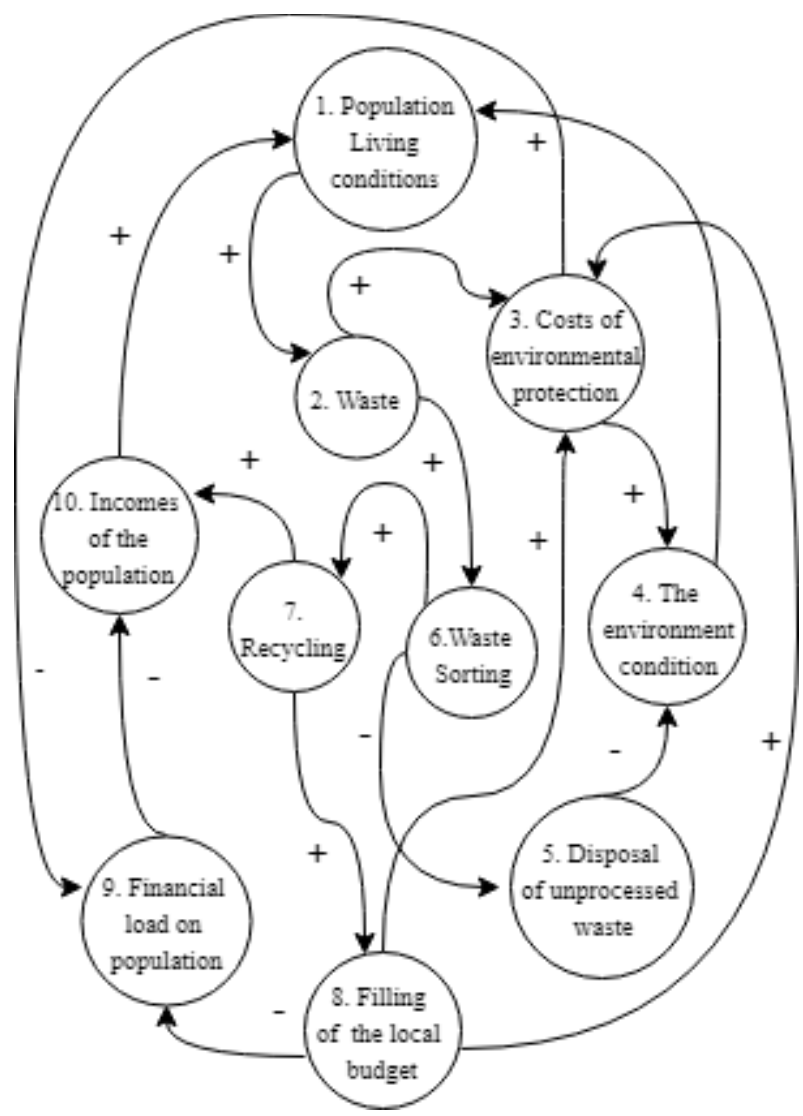

Fig. 2. Cognitive model of waste management with the prevalence of waste sorting and recycling

The contours in the cognitive map correspond to the feedback loops. Contours with negative feedback suggest that there is a tendency towards stabilization of the situation, bringing the system into balance $[13,14]$. In such contours, when the parameters change, the system return itself to balance.

A waste management strategy is proposed, with waste sorting and recycling prevailing, and only a small fraction of non-recyclable waste is sent to landfill for disposal.

\section{STRUCTURE ANALYSIS OF DIFFERENT COMPONENTS STATE CHANGES OF THE SYSTEM FOR VARIOUS STRATEGIES OF WASTE MANAGEMENT}

Qualitatively estimate the behavior of the various process condition of the system components for different waste management strategies.

The following provisions are postulated, according to [15]. The components of the system state vector may be only the elements of the set $\{-1,0,+1\}$. The value " 1 " corresponds to a positive state change; " 0 " corresponds to the unchanged state; "-1" indicates deterioration.

1) If during the calculations the value of the state vector component exceeds the value " +1 ", it is replaced with the value "one".

2) If during the calculations the value of the state vector component takes a value less than "-1", it is replaced with "minus one". 
3) If during the calculations the value of the state vector takes the value "zero", it remains unchanged.

4) It is considered that the value of the state vector component corresponding to the component of the system that were affected, subsequently remains unchanged.

Strategies with the prevalence of waste disposal corresponds to the model presented in Figure 1. The component, which changes the status is "Financial load on population".

It is required to assess how the change in the status of one of the components will affect the status of the waste management system. It is necessary to use the following ratio.

$$
\left[C_{1}, C_{2}, \ldots C_{7}\right]_{H}=\left[C_{1}, C_{2}, \ldots C_{7}\right]_{C} *\|H\|
$$

This sign-oriented graph corresponds to a matrix of the form:

$$
\|H\|=\left[\begin{array}{ccccccc}
0 & 1 & 0 & 0 & 0 & 0 & 0 \\
0 & 0 & 1 & 0 & 0 & 0 & 0 \\
0 & 0 & 0 & -1 & 1 & 0 & 0 \\
1 & 0 & 0 & 0 & 0 & 0 & 0 \\
0 & 0 & 0 & 1 & 0 & 1 & 0 \\
0 & 0 & 0 & 0 & 0 & 0 & -1 \\
1 & 0 & 0 & 0 & 0 & 0 & 0
\end{array}\right] .
$$

This matrix characterizes the relationship between nodes in the graph shown in Fig. 1.

$\left[C_{1}, C_{2}, C_{3}, C_{4}, C_{5}, C_{6}, C_{7}\right]-$ state vector of the graph nodes. The index of the vector " $\mathrm{H}$ " characterizes the values of the components of the vector at the $(\mathrm{k}+1)$ iteration. The "C" index characterizes the values of the components of the vector at the $\mathrm{k}$ iteration.

At the initial time to the component "Financial load on population" is made a constant impact. Namely, after the adoption of the federal law about the transition to a new system of solid municipal waste management, it was decided to entrust pay for removal and disposal of waste on the shoulders of citizens, raising the tariffs.

$[0,0,0,0,0,1,0]$ - the initial state vector of the system components at impact on component 6 .

$[0,0,0,0,1,-1]$ - the transformed state vector corresponding to the first iteration, the transformation of the state vector corresponding to the first iteration is due to the fifth postulated position. Due to the fact that the transformed state vector at iteration 9 corresponds to the transformed state vector at iteration 5 , it is concluded that the vibrational state achieved. The results are shown in Fig. 3.

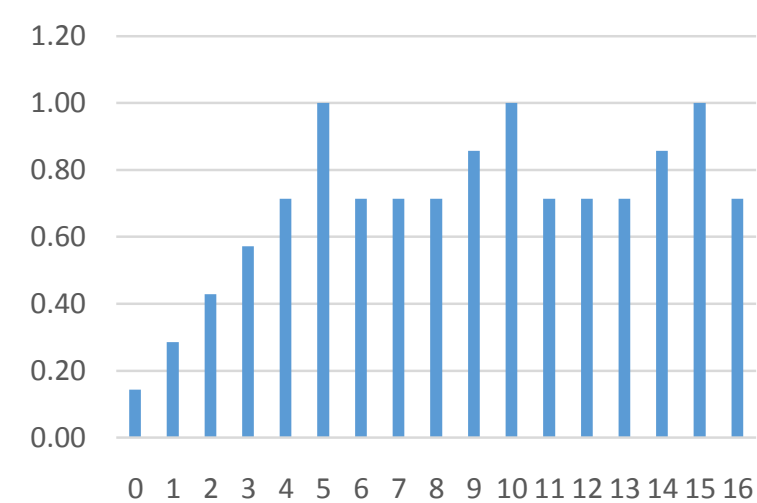

Fig. 3. The condition of the system in the impact on factor 6 (Financial load on the population) at realization of strategy of waste management with the prevalence of waste disposal

The presence of positive and negative feedback is a formal sign of a nonlinear system. The presence of positive and negative feedback contours explains the process of system status changing, which may be converging, diverging, or oscillating for a given structure of the system components status depending on the point of impact.

The results of the first graph (Fig. 3) show an example of the fact that an increase of the "financial load on the population" leads to an oscillatory process in the system, that means that the situation does not improve in general. Obviously, this situation is undesirable from a waste management point of view.

Let's carry out the similar procedure for states changing of the 6 and 7 nodes of the graph for the system corresponding to Figure 2.

At the initial time to the components "Waste Sorting" and "Recycling" are made a constant impact. This means, that impact of node 6 (Waste Sorting) and node 7 (Recycling) in the model of waste management with the prevalence of waste sorting and recycling (Fig. 2) are increase.

$[0,0,0,0,0,1,1,0,0,0]-$ the initial state vector of the system components at impact on component 6 and 7.

This matrix characterizes the relationship between nodes in the graph shown in Fig. 2.

$$
\|H\|=\left[\begin{array}{cccccccccc}
0 & 1 & 0 & 0 & 0 & 0 & 0 & 0 & 0 & 0 \\
0 & 0 & 1 & 0 & 0 & 1 & 0 & 0 & 0 & 0 \\
0 & 0 & 0 & 1 & 0 & 0 & 0 & 0 & 1 & 0 \\
1 & 0 & 0 & 0 & 0 & 0 & 0 & 0 & 0 & 0 \\
0 & 0 & 1 & -1 & 0 & 0 & 0 & 0 & 0 & 0 \\
0 & 0 & 0 & 0 & -1 & 0 & 1 & 0 & 0 & 0 \\
0 & 0 & 0 & 0 & 0 & 0 & 0 & 1 & 0 & 1 \\
0 & 0 & 1 & 0 & 0 & 0 & 0 & 0 & -1 & 0 \\
0 & 0 & 0 & 0 & 0 & 0 & 0 & 0 & 0 & -1 \\
1 & 0 & 0 & 0 & 0 & 0 & 0 & 0 & 0 & 0
\end{array}\right] .
$$


$[0,0,0,0,-1,1,1,1,0,1]-$ the transformed state vector corresponding to the first iteration.

$[1,1,1,1,-1,1,1,1,1,1]-$ the transformed state vector corresponding to the 3 iteration.

Due to the fact that the transformed state vector at iteration 3 corresponds to the transformed state vector at iteration 4 and iteration 5 , it is concluded that the vibrational state achieved. The results are shown in Fig. 4.

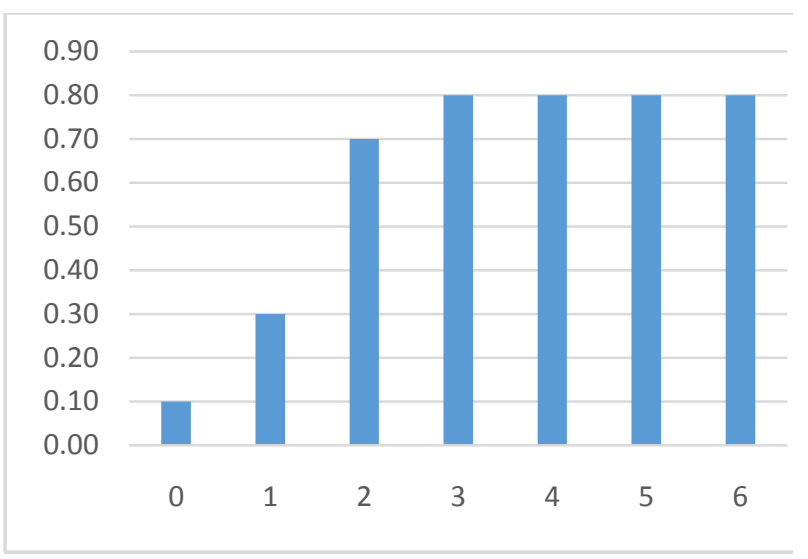

Fig. 4. The condition of the system in the impact on factor 6 and 7 (Waste sorting and Recycling) at realization of strategy of waste management with the prevalence of waste sorting and recycling

On the Fig. 4 the system, where presence sorting of waste and recycling, is in a stable condition.

At estimation of change scenarios of a state both separate component, and systems in general, it is necessary to consider that, if the state of any node is changed, all other associated node are also changed, these changes entail further transformations taking into account relations signs. After a different number of steps, the modified components it selves act on the source node.

An analysis of feedback loops can provide useful information about system behavior. If in a cognitive map most contours increase deviations, then minor perturbations can be gradually enhanced and the system will become unstable. The presence of a negative feedback mechanism in the system makes it more resistant to random change of parameters. Positive contours, on the other hand, require close attention and constant managerial influences to achieve targets.

The given example illustrates the provision about consequences for a system depend on state of which component changed.

Carrying out the similar analysis helps to identify at a qualitative level possible scenarios of state change both of individual components and the system in general.

\section{CONCLUSION}

Today in Russia, in general, and in the Republic of Bashkortostan, in particular, there is a significant increase of waste, which, first of all, is due to the high rates of social and economic development of society. The paper discusses the problem situation in municipal solid waste management on the basis of the intersubjective and converged management theory in the interests of the various stakeholders. The paper expressed understanding of the problem situation through cognitive models.

The main results of the research are:

- The significant factors for modelling have been identified;

- Cognitive maps that correspond to the different strategies for the municipal solid waste management in industrialized areas have been constructed;

- Based on the cognitive model, various scenarios and strategies for resolving a problem situation have been worked out. The primary qualitative analysis of the problem situation, which identify the relationship and influence of various factors is made. This analysis reduces the level of uncertainty in waste management.

\section{ACKNOWLEDGMENT}

This work was supported by a grant № 18-08$00885 \mathrm{~A}$ "Methodological foundations of multicriteria management of the process of choosing the location of industrial waste processing enterprises based on the provisions of evergetics" from the Russian Foundation for Basic Research.

\section{REFERENCES}

[1] L.R. Chernyakhovskaya, "Decision support in management of hardware-software complex functional safety on the basis of ontological engineering" / Gvozdev, V.E., Chernyakhovskaya, L.R., Davlieva A.S. // Proc. of International Russian Automation Conference, RusAutoCon 2018, Russia, Sochi, 2018. P.1-5.

[2] Human factor in management / O.P. Kuznetsov, A.A. Kulinich, A.V. Markovskiy -, M.: KomKniga, 2006. - 344p. (in Russian)

[3] Mysteries of the nature. Synergetrics: the doctrine about interaction / Haken G. - Moscow-Izhevsk: Institute of computer researches, 2003. -320 p.

[4] Non-uniform actor and daily occurrence as key concept of an evergetika / Vittich V.A.. - Samara: IPU RAN, 2014. - 12 p. (in Russian)

[5] V.A. Vittich, "Problems of evergetics" // Problemy upravleniya, 2014, № 4. P 69-71. (in Russian)

[6] The Republic target program "Improvement of a Control System of Municipal Solid Waste in the Republic Bashkortostan for 2011-2020" approved by the resolution of the government of the Republic Bashkortostan 18.11.2011 №412. - Ufa, 2011. - 33 p. (in Russian)

[7] The territorial scheme of the waste handling, including solid municipal waste in the Republic Bashkortostan, approved by the resolution of the government of the Republic Bashkortostan 03.11.2016 №480. - Ufa, 2016. - 302 p. (in Russian)

[8] C.E. Pelaez, J.B. Bowles, |Using fuzzy cognitive maps as a system model for failure modes and effects analysis // Information Sciences. Vol. 88, Issues 1-4, January 1996. P. 177-199.

[9] Ritu Soni, Ashpinder Preet. Cognitive Approach to Root Cause Analysis for Improving Quality of life: A case study 
for IT Industry // International journal of informative and futuristic research (Online). Vol. 1 Issue 1, August September 2013. $-8 \mathrm{p}$.

[10] V.E. Gvozdev, "Information support of technogenic safety management on the basis of mathematical modeling and GIS technologies" / V.E. Gvozdev, O.I. Khristodulo, D.V. Blinova // Proc. of 2nd International Conference on Industrial Engineering, Applications and Manufacturing, ICIEAM 2016 , Russia, Chelyabinsk, 2016. P.1-4.

[11] O.I. Khristodulo, "Spatial information processing for decision-making support of siting of technogenic hazards using computer technologies"/ Khristodulo O.I., Gvozdev V.E., Davletbakova Z. // Proc. of 2nd International Conference on Industrial Engineering, Applications and Manufacturing, ICIEAM 2016, Russia, Chelyabinsk, 2016. P.1-5.

[12] V.E. Gvozdev, "Statistical analysis of time of establishing steady phases of functioning of complex hardware-software systems" / V.E. Gvozdev, D.V. Blinova, D.R. Akhmetova // Proc. of International Russian Automation Conference, RusAutoCon 2018, Russia, Sochi, 2018. P.1-5.

[13] V.E. Gvozdev, "Control of component alterations according with the target efficiency of data processing and control system" / V.E. Gvozdev, M.B. Guzairov, D.V. Blinova, A.S Davlieva, // Proceedings of the International conference Information Technology and Nanotechnology. Session Data Science (Samara, Russia, 24-27 April, 2017): 2017. P. 11-16.

[14] M.B. Guzairov, "Analysis of Properties Hardware-Software System in Efficiency Index Under Uncertainty Component Structures" / M.B. Guzairov, V. E. Gvozdev, A. Davlieva, V. Teslenko // Proceedings of the Vth International workshop \&quot;Critical infrastructures: Contingency management, Intelligent, Agent-based, Cloud computing and Cyber security\&quot; (IWCI 2018). P. 73-77.

[15] A.V. Markovskiy, "Using of structure analysis methods at cognative map preparation"/ Proc. of International Conference on Cognative Analysis and System Control, CASC 2009, Russia, Moscow, 2009. P. 41-46. (in Russian) 